\title{
Energy and economic comparison of three optical systems adopted in a point-focus CPV system
}

\author{
Carlo Renno ${ }^{1}$ (1)
}

Received: 17 May 2021 / Accepted: 4 February 2022 / Published online: 26 February 2022

(c) The Author(s) 2022

\begin{abstract}
The concentrating photovoltaic (CPV) systems allow good results for generation of clean energy at competitive costs, but a careful selection of the optical system is essential to obtain energy and economic advantages. Hence, three different pointfocus optics (parabolic mirror, spherical mirror and a commonly used Fresnel lens) characterized by same dimensions are compared in this paper from energy and economic point of view in order to identify the most convenient in terms of unit cost of electrical power. The optical concentration factor, the maximum values of triple-junction (TJ) cell electrical power and temperature are experimentally measured for each optical system, and successively, the unit cost of electrical power is calculated. The parabolic mirror results the least convenient because it guarantees almost the same performances of a spherical optics but with costs of about 2.7 times higher than it. The Fresnel lens presents a value of the unit cost of electrical power near to the spherical mirror, but its much lower optical efficiency implies a necessary area for the CPV plant about three times larger. Moreover, a forecast of the increase in the CPV plant power capacity in Italy and the consequent decrease in the unit cost of electrical power in two possible scenarios, optimistic and pessimistic, is realized. A reduction of the unit cost of electrical power, between 13 and 30\%, is expected for the CPV systems.
\end{abstract}

Keywords Concentrating photovoltaic system $\cdot$ Point-focus configuration $\cdot$ Refractive and reflective optics $\cdot$ Energy and economic comparison

$\begin{array}{ll}\text { List of symbols } \\ A & \text { Area }\left(\mathrm{m}^{2}\right) \\ C_{\mathrm{geo}} & \text { Geometrical concentration factor } \\ C_{\mathrm{opt}} & \text { Optical concentration factor } \\ c_{\mathrm{os}} & \text { Cost of optical system }(€) \\ c_{P_{\mathrm{el}}} & \text { Unit cost of electrical power }(€ / \mathrm{W}) \\ \mathrm{CPV} & \text { Concentrating photovoltaic system } \\ \mathrm{CPV} / \mathrm{T} & \text { Concentrating photovoltaic and thermal system } \\ \mathrm{DNI} & \text { Direct normal irradiance }\left(\mathrm{W} / \mathrm{m}^{2}\right) \\ N & \text { Number } \\ P & \text { Electric power }(\mathrm{W}) \\ P_{\text {el, CPV-p }} & \text { CPV peak electrical power }(\mathrm{W}) \\ P_{\mathrm{el}, \mathrm{c}-\mathrm{p}} & \text { TJ cell peak electrical power }(\mathrm{W}) \\ R_{\mathrm{c}} & \text { Concentrated solar radiation }\left(\mathrm{kW} / \mathrm{m}^{2}\right) \\ T & \text { Temperature }\left({ }^{\circ} \mathrm{C}\right)\end{array}$

Technical Editor: Monica Carvalho.

Carlo Renno

crenno@unisa.it

1 Department of Industrial Engineering, University of Salerno, Via Giovanni Paolo II, 132, 84084 Fisciano, Salerno, Italy

$\begin{array}{ll}\text { TJ } & \text { Triple-junction cell } \\ \eta & \text { Efficiency } \\ \text { Subscripts } & \\ \text { c } & \text { Cell } \\ \text { conc } & \text { Concentrator } \\ \text { el } & \text { Electric } \\ \text { env } & \text { Environmental } \\ \text { opt } & \text { Optical } \\ \text { os } & \text { Optical system } \\ \text { p } & \text { Peak }\end{array}$

\section{Introduction}

The energy demand in the world is significantly increasing due to population growth and industrial evolution [1]. However, the burning of the traditional fossil fuels, which are available and commonly used for satisfying the world energy demand, is causing environmental problems such as climate change, global warming, air pollution and acid rain [2]. Hence, there is an urgent need for the 
development of renewable energy technologies in order to deal with the political, economic and environmental challenges in electricity production [3]. Even if currently the traditional energy conversion technologies based on fossil fuels are often more convenient, it can be expected in the next future that some renewable technologies will become economically competitive with conventional ones [4]. In particular, the solar energy could be an optimal option because of several reasons. First, it is the most abundant source of renewable energy and is not exhaustible, giving solid and increasing output efficiencies in comparison with other sources of energy [1]. Moreover, the solar energy can be simultaneously converted into different energy vectors [5]. In fact, the photovoltaic-thermal (PV/T) systems can simultaneously produce electrical and thermal energy, decreasing electricity production costs and increasing the overall use of solar energy. An effective way to maximize efficiency levels is to adopt concentrating photovoltaic (CPV) or concentrating photovoltaic and thermal (CPV/T) systems [6]. These systems use optical devices such as mirrors or lenses able to convey the solar radiation on smaller multi-junction (MJ) cells and to obtain higher electrical power due to their higher electrical conversion efficiency [7]. On the other hand, the increase in the sunlight concentration leads to an increase in the cell temperature. However, exploiting the thermal energy recovery from the solar cells by means of an active cooling system [8], it is possible to obtain an increase in electrical efficiency producing simultaneously electric and thermal energy [9]. Hence, CPV and CPV/T systems allow good results at competitive costs for generation of clean energy [10], but a careful selection of the optical system typology and of its concentration factor is fundamental to obtain energy and economic advantages [11]. Several types of optical systems have been developed. They differ in terms of geometry, methods and levels of concentration and each of them presents advantages and disadvantages. Hence, the optical systems can be classified into several ways. According to their principle of operation, optical systems can be divided into refractive and reflective optics [12]. Moreover, they can be classified according to the achievable level of concentration: low ( $<10$ suns), medium (10-100 suns), high (100-2000 suns) and ultrahigh (2000-42,000 suns) [13]. Depending on whether the sunlight is conveyed on small or larger area or along line, optical systems can be classified into point-focus, dense array and line-focus [14]. Referring to the point-focus optics, in this paper the main technologies used are considered and a comparison from the energy and economic point of view is realized for three different typologies of optics: Fresnel lens, parabolic mirror and spherical mirror. The principal aim is to evaluate the optical systems most convenient in terms of unit cost of electrical power.

\section{Experimental analysis of optics adopted in a point-focus CPV system}

\subsection{Typologies of optics}

Because the CPV systems are still in stage of development, several optical systems are tested to improve their energy and economic performances [15]. As for the point-focus optical systems, most applications use refractive optics such as the Fresnel lens [15]. The most common Fresnel lens is generally made of PMMA, but other materials are being analyzed [15]. A Fresnel lens conveys sunlight by refraction on the solar cell; it requires the presence of secondary optics to avoid chromatic aberration problems. An interesting analysis of the experimental methods used to evaluate the optical performances of a Fresnel lens is reported in [16]. In [17] a Fresnel lens conveys the sunlight on planoconcave lens which works as secondary optics to uniform the concentrated solar radiation on MJ solar cell. In [18], both electrical and thermal parameters are analyzed to evaluate the potential energy production of CPV system that uses a Fresnel lens as primary optics.

On the contrary, the point-focus reflective optics are less diffused but can increase the CPV system performances. A reflective optics generally is subjected to an appropriate reflective treatment (protected aluminizing treatment) to reflect the solar radiation within the TJ cell operating wavelength range. A typical point-focus reflective optics is the parabolic dish and different studies investigate models able to determine the parabolic dish opto-geometrical parameters [19]. An interesting application is discussed in [20] where double reflection Cassegrain CPV with parabolic dish and hyperbolic mirror, is studied. A similar configuration is analyzed in [21] where the primary parabolic dish concentrates the solar radiation at its focal point, and the secondary hyperbolic reflector redirects the solar radiation to glass homogenizer and solar cell.

The economic performances of reflective point-focus optics can be improved considering a spherical shape rather than a parabolic. In fact, from a study commissioned by the authors [22], it has emerged that considering very small size of solar cell, spherical mirror is to be preferred to parabolic from a technical-economic point of view. Even if it requires secondary optics to overcome the spherical aberration problem, the total cost of a spherical optical system can be much lower with respect to parabolic mirror of the same dimensions because it results easier to produce. Hence, the main aim of this paper is to compare the three mentioned types of point-focus optics (parabolic mirror, spherical mirror and 
Fresnel lens) presenting the same diameter. The three optical systems are compared also from an energy and economic point of view to identify the most convenient in terms of electrical power unit cost.

\subsection{Experimental point-focus CPV system}

The experimental CPV plant, shown in Fig. 1, has been realized at the Applied Thermodynamics Laboratory of University of Salerno (Italy). It is a point-focus CPV system that can accommodate more typologies of optics both refractive and reflective. The refractive optics is a Fresnel lens made of PMMA with diameter and thickness, respectively, equal to $30 \mathrm{~cm}$ and $0.4 \mathrm{~cm}$ and a focal distance of $23.9 \mathrm{~cm}$; the reflective optics present the same diameter. The primary optics convey the solar radiation on the receiver consisting of TJ solar cell and passive finned cooling system. The TJ solar cell is the same for each receiver and is constituted by $\mathrm{InGaP} /$ $\mathrm{GaAs} / \mathrm{Ge}$ and presents an area equal to $10.0 \times 10.0 \mathrm{~mm}^{2}$. For all TJ cells, a pyramid-shaped light-guide, of height equal to $75.0 \mathrm{~mm}$ and presenting major base area and minor base area, respectively, equal to $16.0 \times 16.0 \mathrm{~mm}^{2}$ and $10.0 \times 10.0$ $\mathrm{mm}^{2}$, is used as secondary optics to avoid chromatic aberration problems and to improve the optical efficiency. A tracking system is adopted in the experimental CPV system to converge the maximum direct normal irradiance (DNI) on

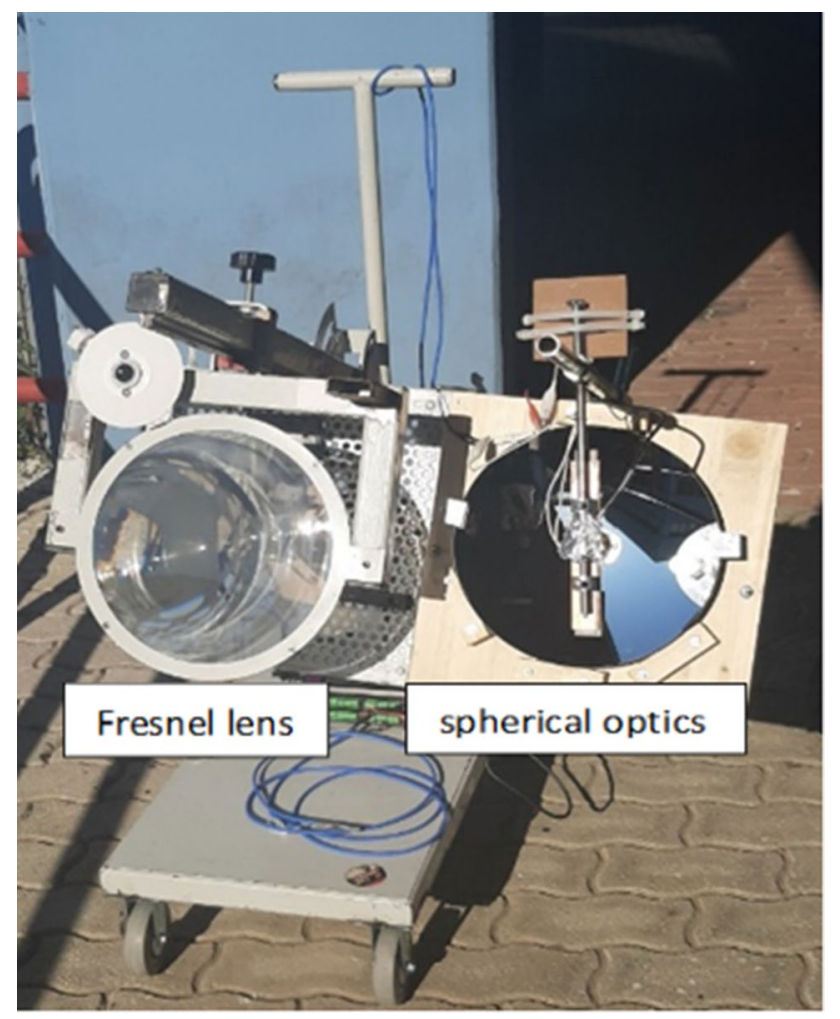

Fig. 1 Experimental plant the receiver. The experimental system allows to move on vertical axis of the receiver in the case of reflective optics and the Fresnel lens in the refractive case. So, the incident solar radiation on the TJ cell can be varied modifying the concentration factor. As for the measurements, a pyrheliometer (accuracy of 2\%) measures the DNI and PT100 thermo-resistances (accuracy of $\pm 0.2^{\circ} \mathrm{C}$ ) measure the cells and outdoor temperatures. A variable electrical load is connected to each cell and an acquisition data system is adopted for the experimental measurements of voltage, current, DNI and temperatures. The experimental calculation of the optical concentration factor $\left(C_{\text {opt }}\right)$ is obtained as ratio between the solar radiation concentrated on TJ cell $\left(R_{\mathrm{c}}\right)$, measured by means of thermal power sensor (accuracy of $\pm 3 \%$ ), and the DNI that represents the incident power flow on the optical system. Hence, $\mathrm{C}_{\mathrm{opt}}$ results independent from the TJ cell electrical performance, while it depends only on the system optical performances. During the measurement of $C_{\text {opt }}$, it is necessary that the solar radiation concentrated on TJ cell and power sensor, is the same. The thermal power sensor presents bimetallic junctions (thermopile). The heat flows in the sensor and determines a voltage proportional to the power absorbed when it flows through the thermopile.

\section{Energy and economic comparison between the point-focus optical systems}

The optical concentration factor $\left(C_{\text {opt }}\right)$ and the optical efficiency $\left(\eta_{\text {opt }}\right)$ of each system are first evaluated. As for the energy performances, the most interesting variables are the TJ cell $\left(T_{\mathrm{c}}\right)$ temperature and its electrical power $\left(P_{\mathrm{el}, \mathrm{c}}\right)$, both experimentally measured. Once evaluated these parameters, the unit cost of electrical power $\left(c_{P_{\mathrm{el}}}\right)$ achievable by means of each optical system, is calculated. Successively, considering the results obtained, the optical systems number $\left(N_{\text {o.s. }}\right)$ and the necessary area $\left(A_{\mathrm{o} . \mathrm{s}}\right)$ for a CPV plant with peak electrical power of $3.5 \mathrm{~kW}$, are also evaluated for the three optics. Finally, a forecast about the increase in the CPV power plant capacity in Italy and the consequent decrease in $c_{P_{\mathrm{el}}}$ in two possible scenarios, optimistic and pessimistic, is shown and discussed.

\subsection{Energy comparison}

The CPV system energy performances depend on the solar concentration levels that the optical system allows to obtain. The geometrical concentration factor $\left(C_{\text {geo }}\right)$ represents the maximum level of concentration theoretically achievable by a given optical system in absence of power losses. It is the ratio between the solar concentrator area $\left(A_{\text {conc }}\right)$ perpendicular to the sunrays and the TJ cell area $\left(A_{\mathrm{c}}\right)$ : 
$C_{\text {geo }}=\frac{A_{\text {conc }}}{A_{\mathrm{c}}}$.

The comparison between the three identified optical systems is realized considering the same dimensions; hence, $C_{\text {geo }}$ is the same for each one. The effective concentration level obtainable by means of an optical system is measured by optical concentration factor $\left(C_{\text {opt }}\right)$ defined as ratio between the solar radiation concentrated on the TJ cell $\left(R_{\mathrm{c}}\right)$ and the DNI:

$C_{\mathrm{opt}}=\frac{R_{\mathrm{c}}}{\mathrm{DNI}}$

$C_{\text {opt }}$ is linked to $C_{\text {geo }}$ by means of the optical efficiency $\left(\eta_{\text {opt }}\right)$, which indicates how much power incident on the concentrator is effectively conveyed to the receiver:

$C_{\mathrm{opt}}=\eta_{\mathrm{opt}} \cdot C_{\mathrm{geo}} \cdot$

Once measured the values of $C_{\text {opt }}$ achievable by means of each optical system, it is possible to evaluate the energy performances in terms of $T_{\mathrm{c}}$ and $P_{\mathrm{el}, \mathrm{c}}$. The TJ cell temperature is a basic parameter for the evaluation of the $\mathrm{CPV} / \mathrm{T}$ system energy performances from the electrical and thermal point of view [23]. In fact, the thermal energy recovery of CPV/T system depends on $\mathrm{T}_{\mathrm{c}}$ that significantly affects also the $\mathrm{TJ}$ cell electrical efficiency. $T_{\mathrm{c}}$ and $P_{\mathrm{el}, \mathrm{c}}$ depend on $R_{\mathrm{c}}$ and then, considering the DNI same values, on the $C_{\mathrm{opt}}$ value achievable by a given optical system. Moreover, $T_{\mathrm{c}}$ depends also on the environmental temperature ( $T_{\text {env }}$ ) [24]; so, it is more correct the increase evaluation of $T_{c}\left(\Delta T_{c}\right)$ with respect to $\mathrm{T}_{\text {env }}$ due to the solar concentration:

$\Delta T_{\mathrm{c}}=T_{\mathrm{c}}-T_{\mathrm{env}}$.

\subsection{Economic comparison}

The economic comparison is realized in the hypothesis that the three optics present the same dimensions. Moreover, every optics requires a secondary optics to uniform the concentrated solar radiation incident on the TJ cell. Hence, it is possible to calculate the unit cost of electrical power $\left(c_{P_{\mathrm{el}}}\right)$ by means of the following equation:

$c_{P_{\mathrm{el}}}=\frac{c_{\mathrm{os}}}{P_{\mathrm{el}, \mathrm{c}-\mathrm{p}}}$

where $c_{\mathrm{os}}$ is the cost of the optical system, that includes the primary and secondary optics, and $P_{\mathrm{el}, \mathrm{c}-\mathrm{p}}$ is the peak electrical power supplied by the TJ cell and experimentally measured.

Moreover, considering the different values of $P_{\text {el,c-p }}$ and $\eta_{\text {opt }}$ reported above for each optics, it is possible to calculate, as first approximation, the number of optical systems and the corresponding area of a CPV plant with a peak electrical power equal to $P_{\mathrm{el}, \mathrm{CPV}-\mathrm{p}}$ :

$N_{\mathrm{os}, \mathrm{CPV}}=\frac{P_{\mathrm{el}, \mathrm{CPV}-\mathrm{p}}}{P_{\mathrm{el}, \mathrm{c}-\mathrm{p}}}$

$A_{\text {os, } \mathrm{CPV}}=A_{\text {o.s. }} \cdot N_{\text {o.s., CPV }}$

where $A_{\text {os }}$ is the area of the single optical system.

Finally, a forecast of the decrease in the unit cost of the electric power in pessimistic and optimistic scenarios, due to a possible increase in CPV power plant capacity in Italy, is presented. In this analysis, the CPV systems are divided into four classes according to the peak electrical power. For each category identified, the unit cost of the electric power supplied by a CPV systems will decrease as a function of the CPV power plant capacity according to the following equation:

$\mathrm{c}_{\mathrm{P}_{\mathrm{el}}}=\alpha \cdot \mathrm{PC}_{\mathrm{CPV}}^{\beta}$

where $\mathrm{PC}_{\mathrm{CPV}}$ indicates the installations of $\mathrm{CPV}$ power plant capacity, and $\alpha$ and $\beta$ are two parameters determined for each category.

\section{Results and discussion}

\subsection{Results of the energy comparison}

As previously reported, the energy performances of a CPV system depend on the levels of solar concentration that its optical system allows to obtain. Considering that the three optics have the same diameter equal to $30.0 \mathrm{~cm}$ and all convey the solar radiation on a TJ cell with an area equal to $10 \times 10 \mathrm{~mm}^{2}$, they present the same $C_{\text {geo }}$ equal to 707 . The effective value achievable of $C_{\text {opt }}$ has been experimentally measured for each optical system comprehensive of secondary optics, and the results are shown in Fig. 2. It can be noted that the two reflective (parabolic and spherical) optics present very similar values of $C_{\mathrm{opt}}$; on the contrary, the Fresnel lens presents a much lower value of $C_{\mathrm{opt}}$ equal to 171 .

Considering the values of $C_{\mathrm{opt}}$ and $C_{\mathrm{geo}}$, it is possible to calculate the optical efficiency for three optics considered: spherical and parabolic mirrors and Fresnel lens (Fig. 3). As shown in Fig. 3, $\eta_{\text {opt }}$ is about three times higher for the two mirrors compared to the lens; in particular, it is equal to $24 \%$ for the Fresnel lens and to $73 \%$ and $75 \%$, respectively, for the spherical and parabolic mirrors. Hence, despite the same dimensions, the three optics present different $\eta_{\text {opt }}$ and $C_{\text {opt }}$ values which affect the CPV system energy performances both from an electrical and thermal point of view. In particular, Fresnel lens conveys sunlight by refraction on solar cell; 
Fig. 2 Values of $C_{\text {opt }}$ and $C_{\text {geo }}$ for the three optical systems

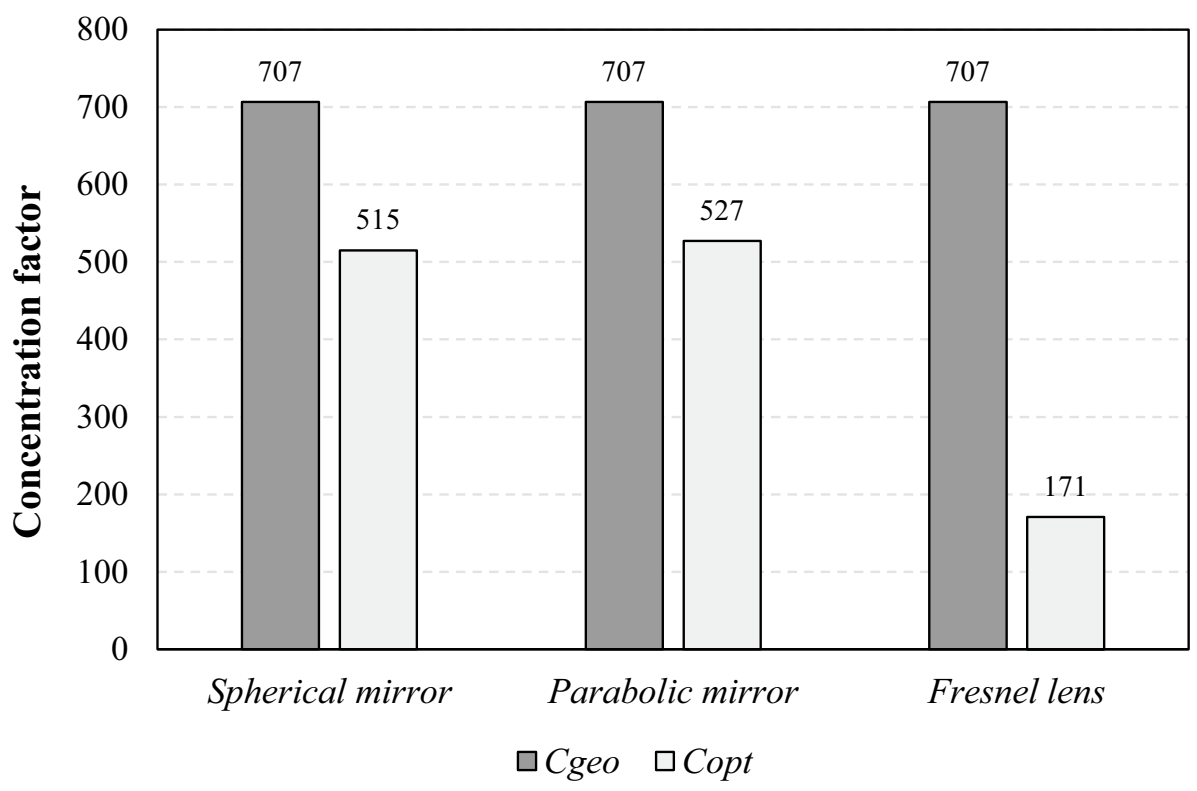

Fig. 3 Values of $\eta_{\text {opt }}$ for the three optical systems

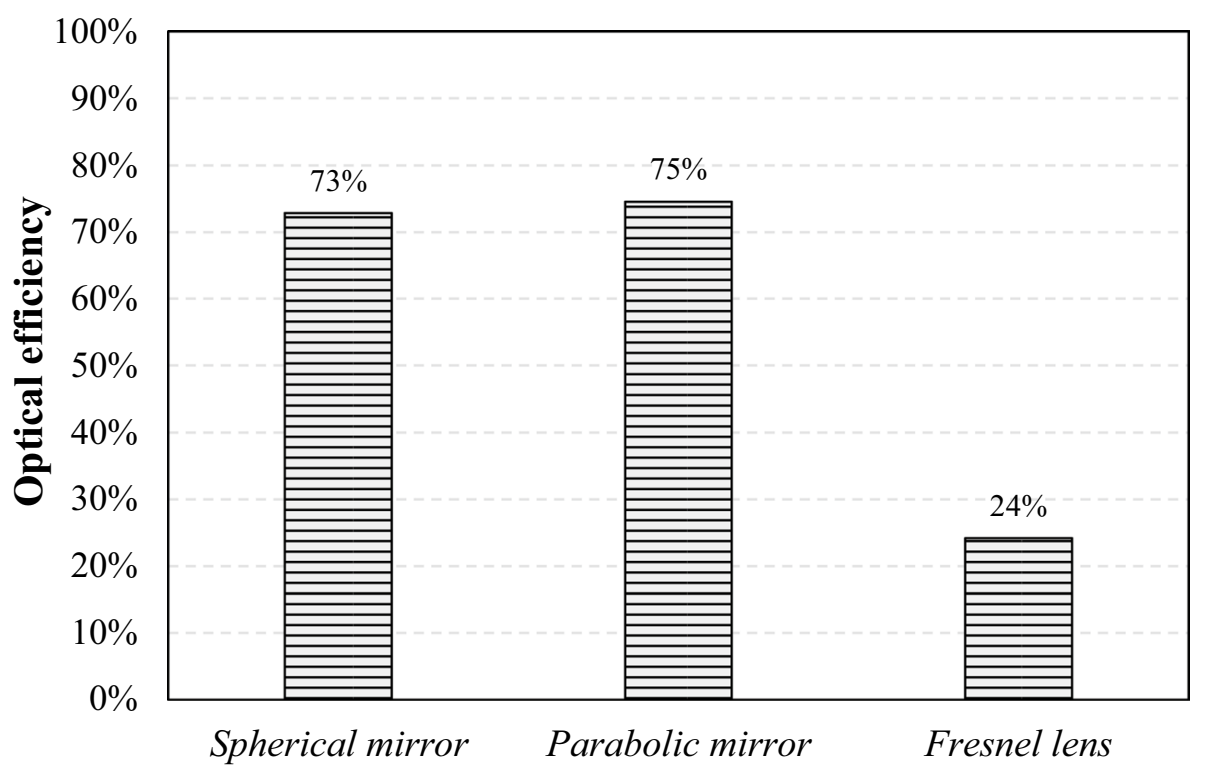

it often requires the presence of secondary optics to avoid chromatic aberration problems. Moreover, the exposure to the sun causes it to heat up and expand accentuating the optical losses.

Referring to the electrical aspects, the maximum values experimentally measured of the electrical power supplied by the TJ cell $\left(P_{\text {el,c-p }}\right)$ are shown in Fig. 4 for each optics. The higher values of $C_{\text {opt }}$ achievable by the spherical and parabolic mirrors allow to obtain higher values of $P_{\text {el,c-p }}$, equal to $14.6 \mathrm{~W}$ and $15.2 \mathrm{~W}$, respectively. On the other hand, the Fresnel lens allows to obtain a value of $P_{\text {el,c-p }}$ of $5.1 \mathrm{~W}$.

As for the thermal aspects, in Fig. 5, the maximum increase in $T_{\mathrm{c}}$ with respect to the environmental temperature $\left(\Delta T_{\mathrm{c}}\right)$ for the three optics, is reported. As shown, the high levels of concentration reached by means of the reflective optics allow to increase the TJ cell temperature of more than $65{ }^{\circ} \mathrm{C}$ with respect to the environmental temperature; this increase is equal to about $40{ }^{\circ} \mathrm{C}$ with the Fresnel lens. The evaluation of $\Delta T_{\mathrm{c}}$ is important also from an economic point of view. In fact, higher are the values of $T_{\mathrm{c}}$, wider the opportunities to exploit the thermal energy recovered in cogeneration applications. 
Fig. 4 Values of $P_{\mathrm{el}, \mathrm{c}-\mathrm{p}}$ measured for the three optical systems
Fig. 5 Maximum values of $\Delta T_{\mathrm{c}}$ measured for the three optical systems
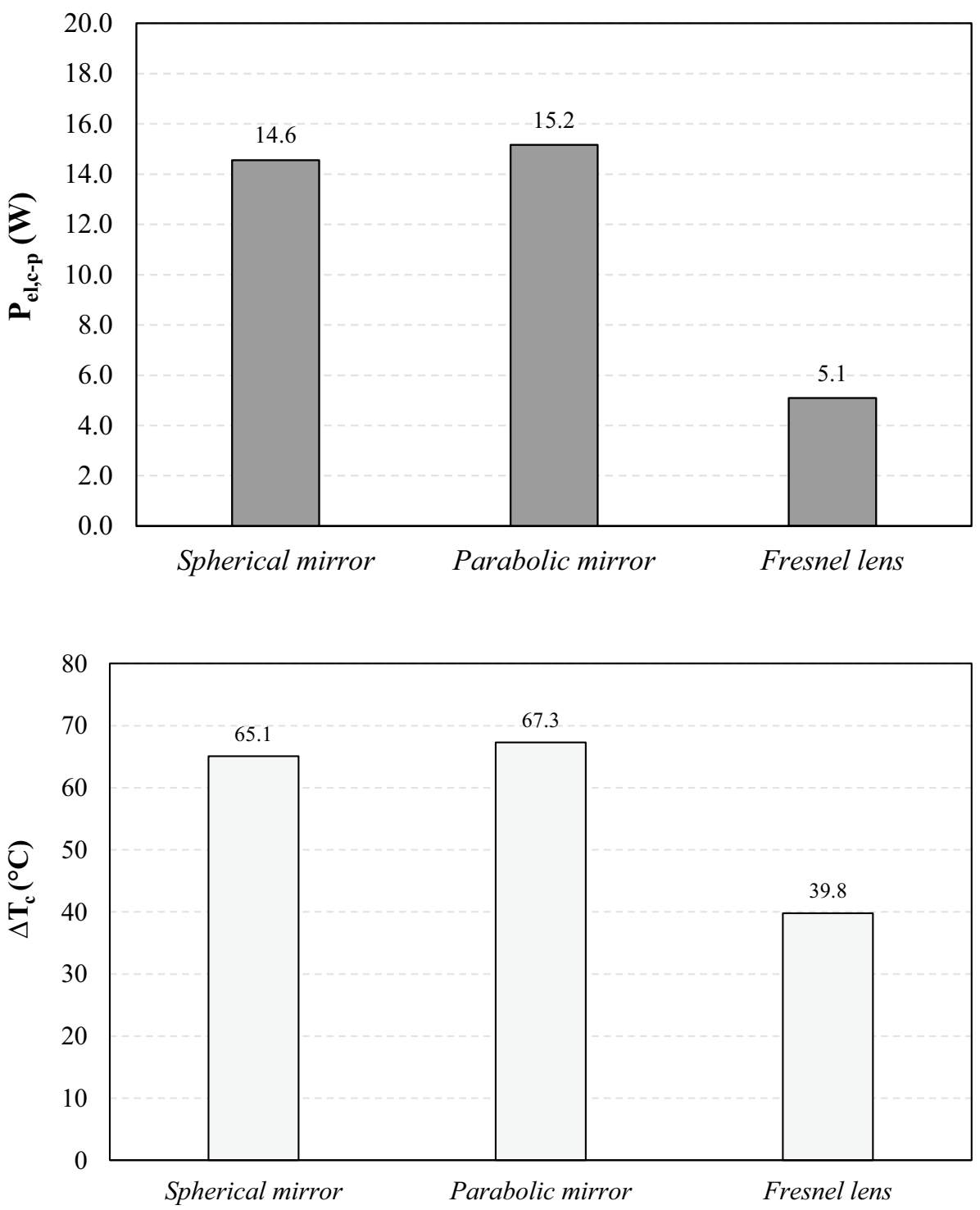

\subsection{Results of the economic comparison}

The experimental evaluation of $C_{\mathrm{opt}}$ and of $P_{\mathrm{el}, \mathrm{c}-\mathrm{p}}$ allows to calculate the unit cost of electrical power $\left(c_{P_{\mathrm{el}}}\right)$ for each optical system according to Eq. 5 .

The cost of each optical system, comprehensive of secondary optics, is reported in Fig. 6. It should be noted that these costs are very high because they refer to ad hoc designed optical systems [22]. It can be noted that the cost of two reflective optics is higher than the refractive one. In particular, the spherical mirror is much more convenient with respect to the parabolic one. In fact, it presents a cost of $2.4 \mathrm{k} €$, which is about $64 \%$ lower than the parabolic optics, and it is characterized by very similar performances.
As for the Fresnel lens, despite presenting the lowest cost, it does not guarantee the same performances of the other two optics analyzed.

A right comparison between the three systems must link their cost to the energy performances. Hence, considering the values of $P_{\mathrm{el}, \mathrm{c}-\mathrm{p}}$ reported in Fig. 4 and the costs reported in Fig. 6, it is possible to calculate by means of Eq. 5 the $c_{P_{\mathrm{el}}}$ value for each optical system, as reported in Fig. 7.

The results obtained show that the spherical mirror is to be preferred to the parabolic one. In fact, the parabolic mirror guarantees almost the same optical and energy performances of the spherical one, but it presents a cost of about 2.7 times higher than it. On the contrary, the costs of spherical optics and Fresnel lens are approximately the 
Fig. 6 Cost of three optical systems comprehensive of secondary optics

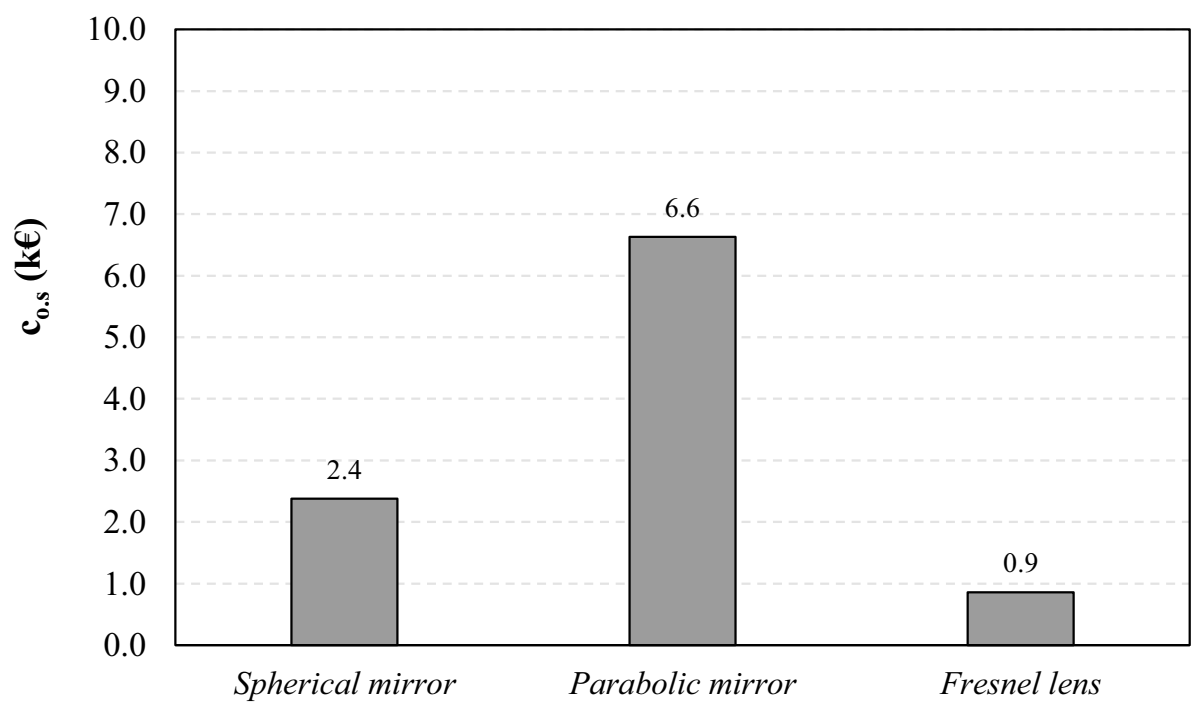

Fig. 7 Unit cost of electrical power $\left(c_{P_{\mathrm{el}}}\right)$ for the three optical systems

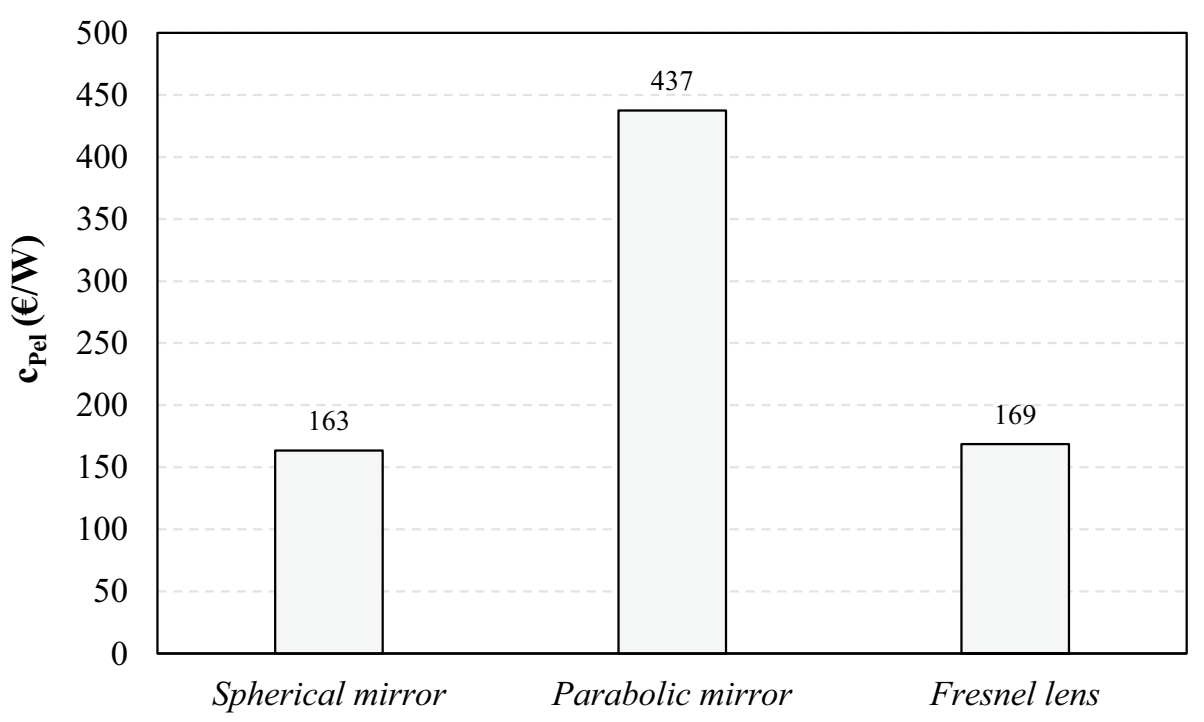

same. However, spherical mirrors are not as much diffused as Fresnel lenses which constitute the commonly used pointfocus optical system. Hence, the cost of spherical mirrors is expected to decrease if their use in CPV systems increases. Moreover, the spherical mirror is characterized by an optical efficiency which is about three times higher than the Fresnel lens. This means that, for the same electrical power, the necessary area for the CPV plant with spherical mirrors is about three times lower with respect to the use of Fresnel lenses. For example, considering the different values of $P_{\mathrm{el}, \mathrm{c}-\mathrm{p}}$ and $\eta_{\text {opt }}$ reported above for each optics, it is possible to calculate, by means of Eqs. 6 and 7, $N_{\text {os }}$ and $A_{\text {os }}$, respectively (Fig. 8), for a CPV plant with a peak electrical power of
$3.5 \mathrm{~kW}$ supplying a domestic user [25]. Despite the three optics have the same dimensions, a higher optical efficiency allows to reduce their number (Fig. 8a) and, consequently, their area (Fig. 8b) for the same electrical output.

The costs shown in Figs. 6 and 7 refer, as previously mentioned, to ad hoc designed optics [22]. In Fig. 9, the CPV unit cost reduction in the years from 2011 to 2019 in Italy is shown [26]. CPV systems are divided into four categories according to the peak electrical power $(<10 \mathrm{~kW}$, $10-100 \mathrm{~kW}, 100-250 \mathrm{~kW}, 10-20 \mathrm{MW})$. It is possible to note that the unit cost of CPV systems is reduced by 2-3 times from 2011 to 2019 for any power range, even reaching the value of about $1 € / \mathrm{W}$. Such cost reduction is due to 
Fig. 8 Number of optical systems $\left(N_{\mathrm{os}, \mathrm{CPV}}\right)$ a and the relative necessary area $\left(A_{\mathrm{os}, \mathrm{CPV}}\right) \mathbf{b}$ for a CPV plant with a peak electrical power of $3.5 \mathrm{~kW}$

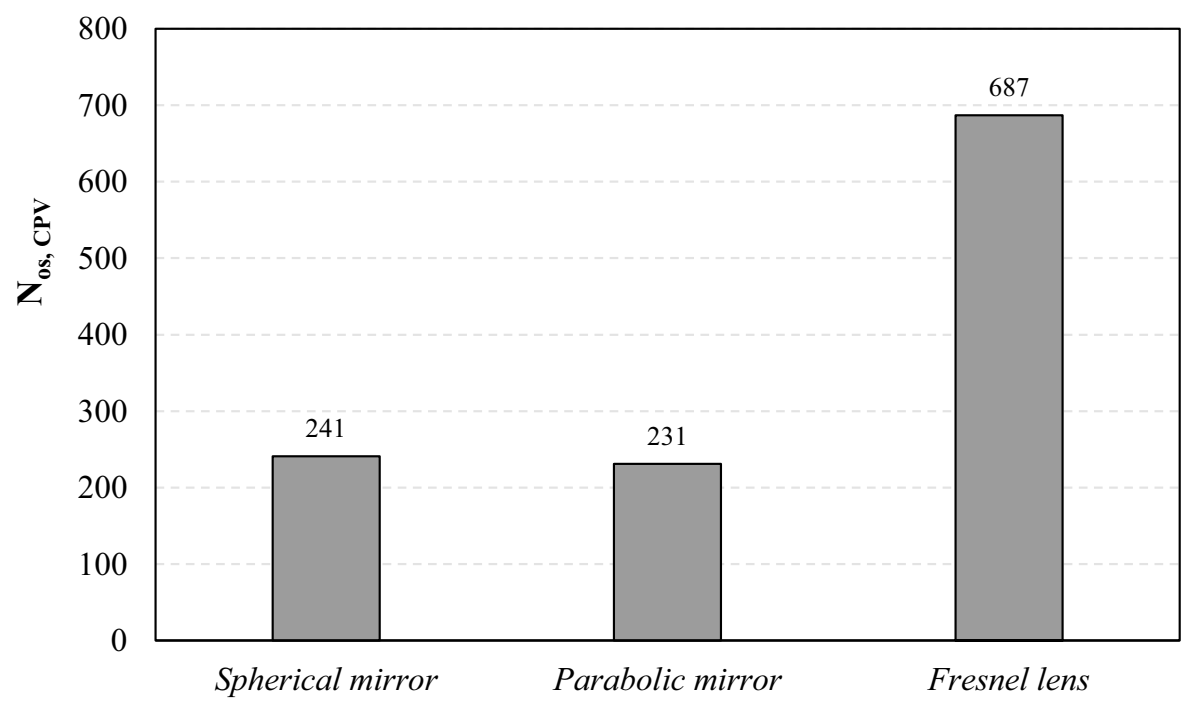

(a)

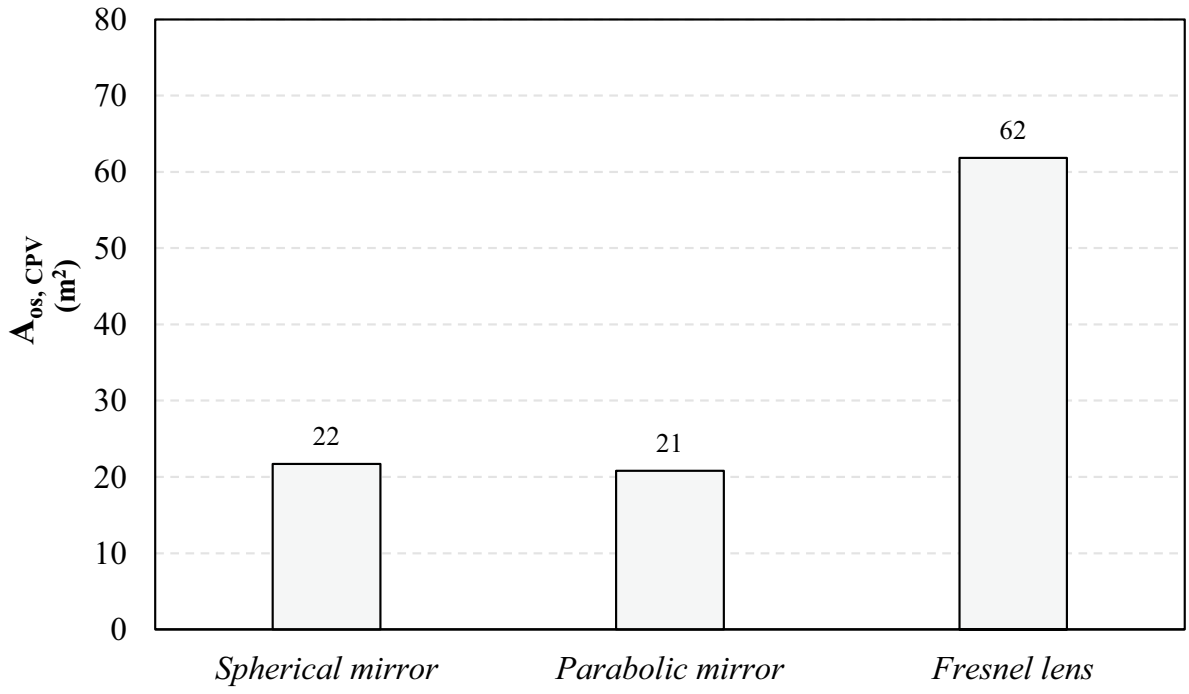

(b) an increasing diffusion of CPV systems during the years. The increase in the CPV power capacity $\left(\mathrm{PC}_{\mathrm{CPV}}\right)$ during the years from 2011 to 2019, together with two forecasts up to 2025 referred, respectively, to pessimistic and optimistic scenario, is shown in Fig. 10 [27]. Hence, in 2025 the CPV power capacity in Italy will be equal to $350 \mathrm{MW}$ in pessimistic scenario and to $800 \mathrm{MW}$ in an optimistic one.

By relating the CPV cost decrease over years reported in Fig. 9 with the $\mathrm{CPV}$ power capacity $\left(\mathrm{PC}_{\mathrm{CPV}}\right)$ per year of
Fig. 10, it is possible to obtain the trends shown in Fig. 11 for the four categories previously defined. It can be noted that the high increase in the CPV power capacity during the years from 2011 to 2019 has determined a decrease in their unit cost of electrical power, which can be described by means of Eq. 8 . The values of the coefficients $\alpha$ and $\beta$ of Eq. 8 are reported in Table 1 for each defined category of CPV system together with the values of $R^{2}$. 
Fig. 9 Reduction of the CPV unit cost $(€ / W)$ from 2011 to 2019 for four categories of power size
Fig. 10 Increase in $\mathrm{CPV}$ power plant capacity $\left(\mathrm{PC}_{\mathrm{CPV}}\right)$ during the years 2013-2019 and two possible forecasts, optimistic and pessimistic, for the years 2020-2025 [27]
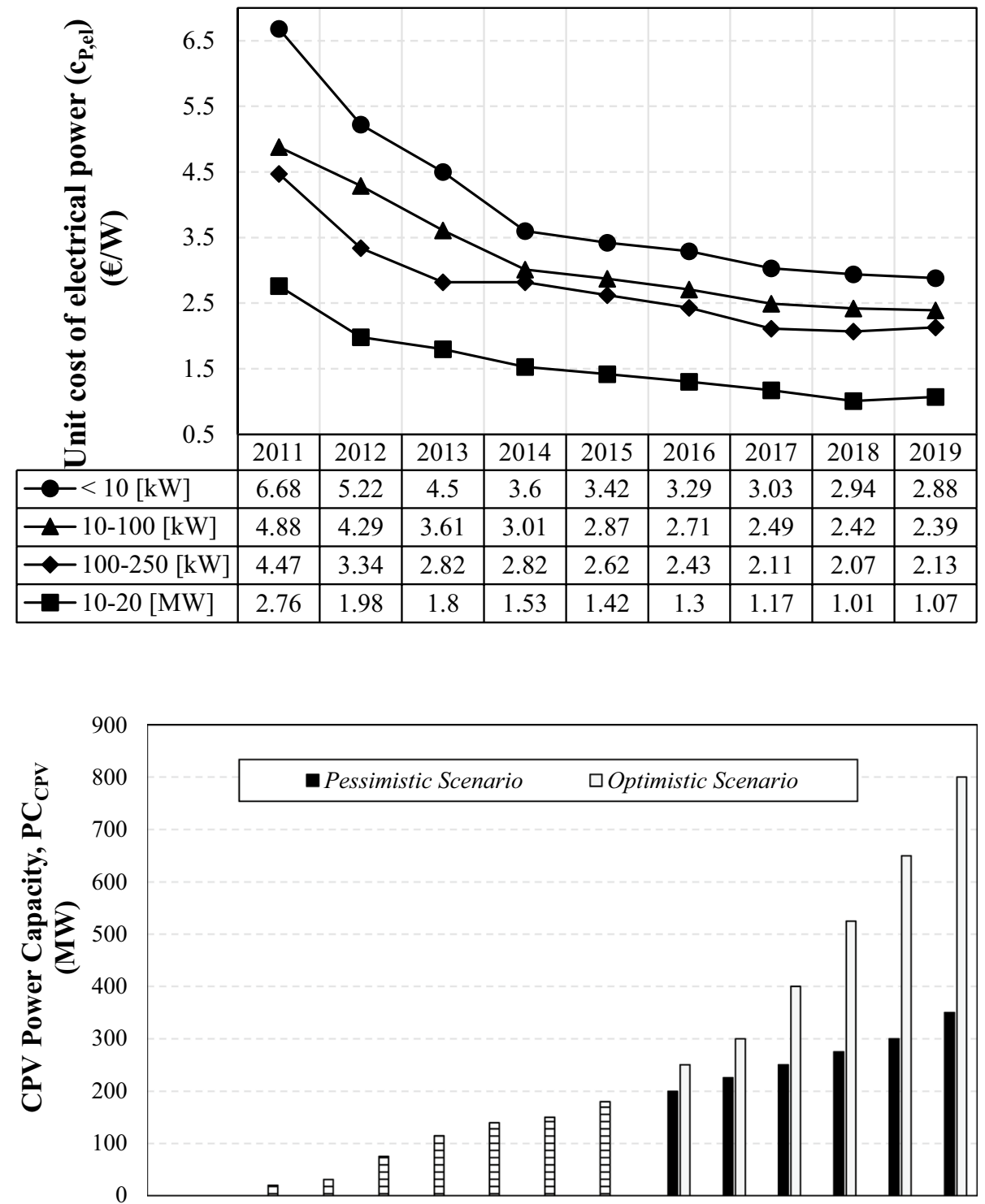

201120122013201420152016201720182019202020212022202320242025
These trends can be extrapolated to estimate the unit cost of the electric power supplied by CPV systems in the years 2020-2025 in the two scenarios, optimistic and pessimistic, defined in Fig. 10. In Fig. 12, the forecasted values of the unit cost of electrical power supplied by a CPV system for the year 2025 in the two scenarios, optimistic and pessimistic, respectively, are reported. As shown, for each category of CPV system it is expected a reduction of its unit cost of electrical power varying from about $13 \%$ in pessimistic scenario to approximately $30 \%$ in an optimistic one, reaching values lower than $3 € / \mathrm{W}$ for electrical powers of CPV system lower than $10 \mathrm{~kW}$ and even lower than $1 € / \mathrm{W}$ for electrical powers included between 10 and $20 \mathrm{MW}$.

\section{Conclusions}

The main aim of this paper has been to compare three types of point-focus optics of a CPV system to identify the most convenient in terms of $c_{P_{\mathrm{el}}}$. The optics considered are: parabolic mirror, spherical mirror and Fresnel lens. The two reflective optics have presented similar values of $C_{\text {opt }}$, equal to 515 for the spherical mirror and 527 for the parabolic one and 171 for the Fresnel lens. Hence, the optical efficiency of two reflective optics is about three times higher with respect to the Fresnel lens equal to $24 \%$. Because of the higher solar concentration, the two mirrors have allowed to reach a $P_{\text {el,c-p }}$ value of about $15 \mathrm{~W}$, much higher than the $5.1 \mathrm{~W}$ achievable by means of the lens. Moreover, they allow to increase the $\mathrm{TJ}$ cell temperature of more than $65^{\circ} \mathrm{C}$ with respect to the 
Fig. 11 Trends of the unit cost of the electric power supplied by CPV systems as function of the CPV power capacity for the four categories defined

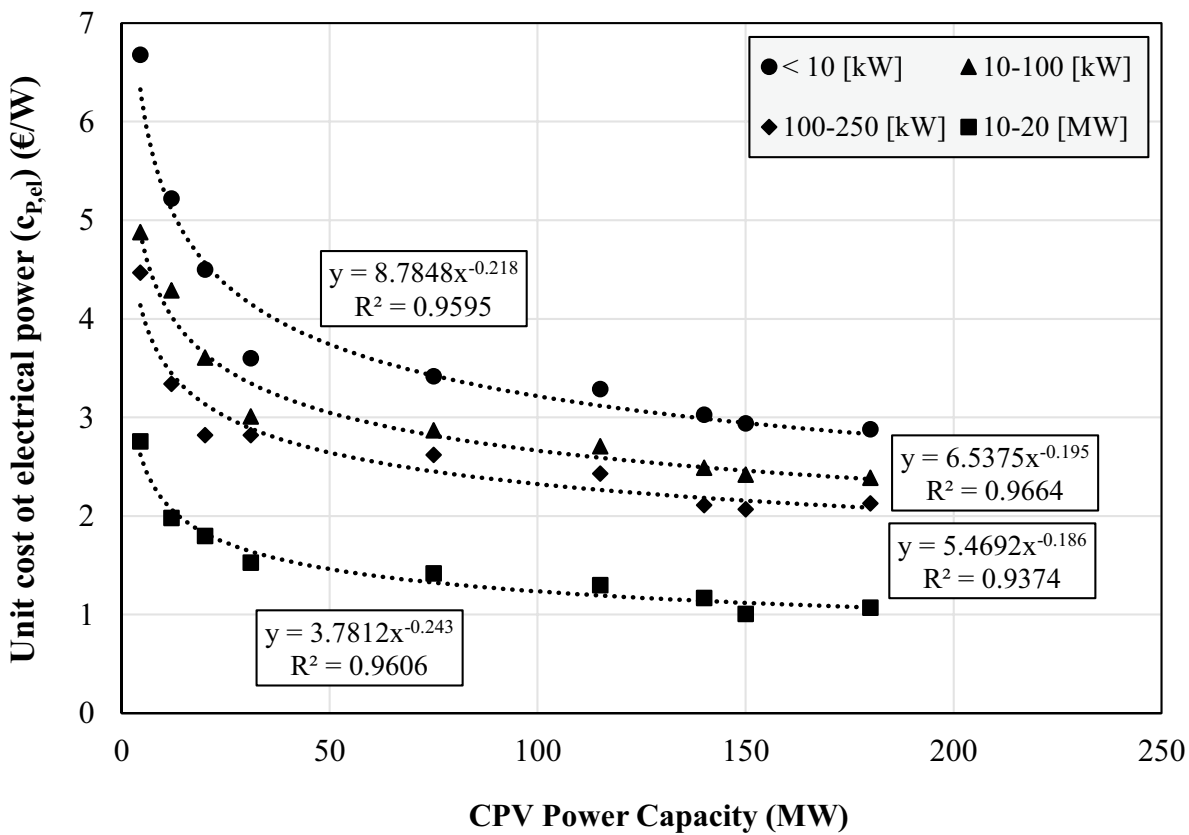

Table 1 Values of the coefficients of the equation describing the trends of the unit cost of the electric power supplied by CPV systems as function of the CPV power capacity for the four categories defined

\begin{tabular}{llll}
\hline CPV category & $\alpha$ & $\beta$ & $R^{2}$ \\
\hline$<10 \mathrm{~kW}$ & 8.785 & -0.218 & 0.9595 \\
$10-100 \mathrm{~kW}$ & 6.538 & -0.195 & 0.9664 \\
$100-250 \mathrm{~kW}$ & 5.469 & -0.186 & 0.9374 \\
$10-20 \mathrm{MW}$ & 3.781 & -0.243 & 0.9606 \\
\hline
\end{tabular}

environmental temperature compared to about $40{ }^{\circ} \mathrm{C}$ of the Fresnel lens. The evaluation of $\Delta T_{\mathrm{c}}$ is important also from an economic point of view, because higher are the values of $T_{\mathrm{c}}$, wider is the opportunity to exploit the thermal energy recovered in cogeneration applications. In the unit cost evaluation of the electrical power, the parabolic mirror has been the least convenient. In fact, it guarantees almost the same performances of a spherical mirror, but with cost about 2.7 times higher than it. The Fresnel lens presents a value of $c_{P_{\text {el }}}$ near to spherical mirror, but its much lower optical efficiency implies a necessary area of the CPV plant about three times larger. The unit cost decrease in CPV systems, divided into four categories in the years from 2011 to 2019 in Italy, has been also reported together with the increase in the CPV power capacity during the same years. The unit cost of the electric power supplied by CPV system in the years 2020-2025 in an optimistic and a pessimistic scenario has been forecasted. In 2025, it is expected a decrease in CPV unit cost of electrical power, variable between 13 and $30 \%$.
Fig. 12 Forecasted values of the unit cost of electrical power supplied by a CPV system for the year 2025 in the two scenarios optimistic and pessimistic

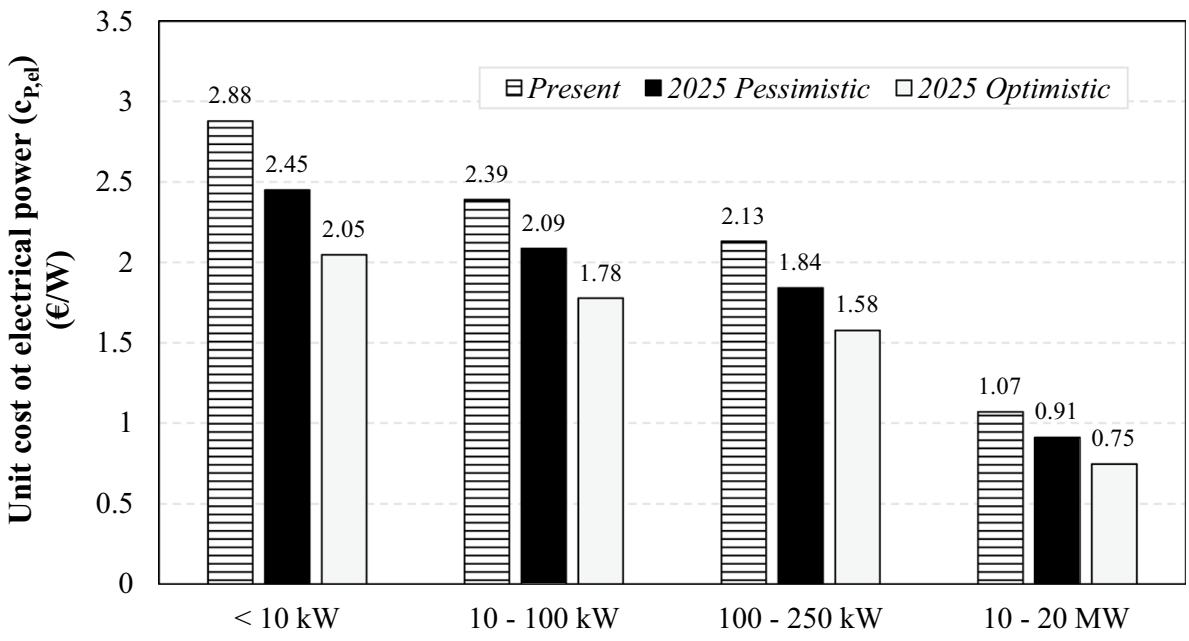


Open Access This article is licensed under a Creative Commons Attribution 4.0 International License, which permits use, sharing, adaptation, distribution and reproduction in any medium or format, as long as you give appropriate credit to the original author(s) and the source, provide a link to the Creative Commons licence, and indicate if changes were made. The images or other third party material in this article are included in the article's Creative Commons licence, unless indicated otherwise in a credit line to the material. If material is not included in the article's Creative Commons licence and your intended use is not permitted by statutory regulation or exceeds the permitted use, you will need to obtain permission directly from the copyright holder. To view a copy of this licence, visit http://creativecommons.org/licenses/by/4.0/.

\section{References}

1. Kannan N, Vakeesan D (2016) Solar energy for future world: a review. Renew Sustain Energy Rev 62:1092-1105

2. Murugan S, Horák B (2016) Tri and polygeneration systems-a review. Renew Sustain Energy Rev 60:1032-1051

3. Sampaio PGV, González MOA (2017) Photovoltaic solar energy: Conceptual framework. Renew Sustain Energy Rev 74:590-601

4. Kandilli C (2013) Performance analysis of a novel concentrating photovoltaic combined system. Energy Convers Manage 67:186-196

5. Wang G, Chen Z, Hu P, Cheng X (2016) Design and optical analysis of the band-focus Fresnel lens solar concentrator. Appl Therm Eng 102:695-700

6. Renno C, D’Agostino D, Minichiello F, Petito F, Balen I (2019) Performance analysis of a CPV/T-DC integrated system adopted for the energy requirements of a supermarket. Appl Therm Eng 149:231-248

7. Renno C (2019) Thermal and electrical modelling of a CPV/T system varying its configuration. J Therm Sci 28:123-132

8. Ortegon JAA, Souza RR, Silva JBC, Cardoso EM (2019) Analytical, experimental, and numerical analysis of a microchannel cooling system for high-concentration photovoltaic cells. J Br Soc Mech Sci Eng 41. Article number 255

9. Renno C (2018) Experimental and theoretical analysis of a linear focus CPV/T system for cogeneration purposes. Energies 11. Article number 2960

10. Radwan A, Okawara S, Ahmed M (2016) Analysis and simulation of concentrating photovoltaic systems with a microchannel heat sink. Sol Energy 136:35-48

11. Xu N, Ji J, Sun W, Han L, Chen H, Jin Z (2015) Outdoor performance analysis of a $1090 \times$ point-focus Fresnel high concentrator photovoltaic/thermal system with triple-junction solar cells. Energy Convers Manage 100:191-200

12. Shanks K, Senthilarasu S, Mallick TK (2016) Optics for concentrating photovoltaics: Trends, limits and opportunities for materials and design. Renew Sustain Energy Rev 60:394-407
13. Chemisana D, Mallick T (2014) Building integrated concentrated solar systems. In: Enteria N, Akbarzadeh A (eds) Solar energy sciences and engineering applications. CRC Press, pp 545-788

14. Serrano-Aguilera JJ, Valenzuela L, Fernandez-Reche J (2016) Inverse Monte Carlo ray-tracing method (IMCRT) applied to line-focus reflectors. Sol Energy 124:84-197

15. Lokeswaran S, Mallick TK, Reddy KS (2020) Design and analysis of dense array CPV receiver for square parabolic dish system with CPC array as secondary concentrator. Sol Energy 199:782-795

16. Victoria M, Askins S, Herrero R, Antón I, Sala G (2016) Assessment of the optical efficiency of a primary lens to be used in a CPV system. Sol Energy 134:406-415

17. Tien NX, Shin S (2016) A novel concentrator photovoltaic (CPV) system with the improvement of irradiance uniformity and the capturing of diffuse solar radiation. Appl Sci 6(9):251

18. Renno C, Petito F, Landi G, Neitzert HC (2017) Experimental characterization of a concentrating photovoltaic system varying the light concentration. Energy Convers Manage 138:119-130

19. Bonsignore G, Gallitto AA, Agnello S, Gelardi FM, Sciortino L, Collura A, Lo U, Milone S, Montagnino FM, Paredes F, Cannas M (2016) CHP efficiency of a 2000 CPV system with reflective optics. In: AIP conference proceedings, pp 1-5

20. Burhan M, Shahzad MW, Ng KC (2017) Long-term performance potential of concentrated photovoltaic (CPV) systems. Energy Convers Manage 148:90-99

21. Kim Y, Jeong HJ, Kim W, Chun W, Han HJ, Lim SH (2017) A comparative performance analysis on daylighting for two different types of solar concentrators: Dish vs. Fresnel lens Energy 137:449-456

22. Gestione Silo, https://www.gestionesilo.it/

23. Rejeb O, Shittu S, Ghenai C, Li G, Zhao X, Bettayeb M (2020) Optimization and performance analysis of a solar concentrated photovoltaic-thermoelectric (CPV-TE) hybrid system. Renew Energy 152:1342-1353

24. Renno C, Petito F (2018) Triple-junction cell temperature evaluation in a CPV system by means of a Random-Forest model. Energy Convers Manage 169:124-136

25. Aprea C, Renno C (2009) Experimental model of a variable capacity compressor. Int J Energy Res 33:29-37

26. Francesca Tilli-GSE/Giosuè Maugeri-RSE. National Survey Report of PV Power Applications in Italy-2018, 2019

27. Fraunhofer Institute for Solar Energy Systems, ISE, with support of PSE Conferences \& Consulting GmbH "Photovoltaics report", 27th August 2018

Publisher's Note Springer Nature remains neutral with regard to jurisdictional claims in published maps and institutional affiliations. 